Tohoku J. Exp. Med., 2011, 224, 173-178

\title{
Higher Serum Free Triiodothyronine Levels within the Normal Range Are Associated with Metabolic Syndrome Components in Type 2 Diabetic Subjects with Euthyroidism
}

\author{
Haruhito Taneichi, ${ }^{1}$ Takayoshi Sasai, ${ }^{1}$ Mio Ohara, ${ }^{1}$ Hiroyuki Honma, ${ }^{1}$ \\ Kan Nagasawa, ${ }^{1}$ Toru Takahashi, ${ }^{1}$ Mototsugu Ishii, ${ }^{1}$ Fumikado Fujiwara, ${ }^{1}$ \\ Mitsuhiro Yamashina, ${ }^{1}$ Takashi Kajiwara, ${ }^{1}$ Noriko Takabe, ${ }^{1}$ Kazuma Takahashi ${ }^{1}$ \\ and Jo Satoh ${ }^{1}$ \\ ${ }^{1}$ Division of Diabetes and Metabolism, Department of Internal Medicine, Iwate Medical University School of \\ Medicine, Morioka, Japan
}

\begin{abstract}
Associations of thyroid hormones with visceral obesity and insulin resistance in obese subjects with euthyroidism have been reported. However, there are no such reports in subjects with type 2 diabetes. The purpose of our study is to observe a relationship between thyroid hormones and components of metabolic syndrome (MetS) in type 2 diabetic subjects with euthyroidism defined by normal thyroid stimulating hormone (TSH) and free thyroxine (FT4) levels. Subjects were 301 Japanese patients with type 2 diabetes. Serum TSH, FT4, free triiodothyronine (FT3), and variables related to MetS were measured. MetS was defined by the Japanese criteria and the criteria of the National Cholesterol Education Program modified for Asians. We found that serum FT3 levels were significantly and positively associated with BMI, visceral fat area, systolic and diastolic blood pressure, estimated glomerular filtration rate, serum triglyceride, and urine $\mathrm{C}$ peptide as a marker of insulin production, whereas negatively with age and $\mathrm{HbA} 1 \mathrm{C}$. In contrast, fewer numbers of variables were associated with serum TSH and FT4 levels. By a multiple regression analysis, FT3 level was independently associated with components of MetS such as visceral fat area, systolic blood pressure, and fasting blood glucose levels. On the other hand, the presence of these MetS components was independently associated with FT3 levels and urine C peptide. In conclusion, these results suggest a significant relationship between serum FT3 levels and components of MetS in type 2 diabetic subjects with euthyroidism, and imply a role of FT3 in MetS in type 2 diabetes.
\end{abstract}

Keywords: euthyroidism; free triiodothyronine; metabolic syndrome; type 2 diabetes; visceral obesity Tohoku J. Exp. Med., 2011, 224 (3), 173-178. (C) 2011 Tohoku University Medical Press

Metabolic syndrome (MetS) consisting of central obesity, glucose intolerance, dyslipidemia and hypertension is a risk factor for atherosclerosis (Eckel et al. 2005). A common basis for these multiple risk factors is insulin resistance induced by deranged secretion of adipokines from visceral adipose tissues, i.e., increase of tumor necrosis factor-alpha and decrease of adiponectin (Matsuzawa 2006). Because thyroid hormones induce various effects on energy homeostasis (Krotkiewski 2002; Nyrnes et al. 2006), lipid and glucose metabolism (Kutty et al. 1978; Torrance et al. 1997), and blood pressure (Fommei and Iervasi 2002), serum thyroid hormone levels may be associated with components of MetS.

Recently, there are several reports indicating an association between thyroid hormone levels and insulin resistance and MetS in euthyroid subjects. Roos et al. (2007) reported that there is an inverse correlation between free thyroxine (FT4) levels and insulin resistance in euthyroid subjects, and implied an increase in cardiovascular risks in subjects with lower thyroid hormone levels even within normal range possibly due to insulin resistance (Bruckert et al. 1999; Roos et al. 2007). Lin et al. (2005) also reported an association of lower serum FT4 levels with MetS in Chinese subjects with normal thyroid function. On the other hand, free triiodothyronine (FT3) levels are moderately increased in obese subjects (Reinehr et al. 2006; De Pergola et al. 2007). FT3 levels are associated with circumference, independently of insulin resistance in healthy and obese women (De Pergola et al. 2007).

However, these reports on an association of thyroid hormone levels with obesity, insulin resistance or MetS were studied in non-diabetic subjects. Therefore, we cross-

Received March 28, 2011; revision accepted for publication May 28, 2011. doi: 10.1620/tjem.224.173

Correspondence: Jo Satoh, Division of Diabetes and Metabolism, Department of Internal Medicine, Iwate Medical University School of

Medicine, 19-1 Uchimaru, Morioka, Iwate 020-8505, Japan.

e-mail: jsatoh@iwate-med.ac.jp 
sectionally analyzed a relationship between thyroid hormones and metabolic syndrome components in subjects with type 2 diabetes.

\section{Subjects and Methods}

Subjects were 301 patients with type 2 diabetes, who were admitted to our hospital for close examination of diabetic complications and better blood glucose control from January 2007 to April 2009 , and who met the inclusion criteria for analysis. The inclusion criteria were euthyroidism [TSH $(0.41-1.43 \mu \mathrm{IU} / \mathrm{ml})$ and FT4 (0.9-1.7 $\mathrm{ng} / \mathrm{dl}$ )], as previously reported (Bruckert et al. 1999) and negative for thyroid autoantibodies such as thyroid peroxidase antibody and thyroglobulin antibody; the exclusion criteria were a history of thyroid diseases and/or medications for thyroid diseases. All patients provided their informed consent to be used their clinical data for analysis in this study. Out of 301 subjects, 52 were treated with diet therapy only, 126 with oral hypoglycemic agents (OHAs), 49 with insulin, and 74 with both OHAs and insulin.

Body weight and height were measured, and body mass index (BMI) was calculated. Blood was obtained from patients who had fasted for more than $12 \mathrm{~h}$. Fasting plasma glucose (FPG), immunoreactive insulin (IRI), hemoglobin A1c (HbA1c), cholinesterase, total cholesterol (TC), triglyceride (TG), high density lipoprotein-cholesterol (HDL-C), low density lipoprotein-cholesterol (LDL-C), thyroid stimulating hormone (TSH), FT4 and FT3 were measured by the Central Laboratory in our hospital. TSH, FT4 and FT3 were measured by an electrochemiluminescence immunoassay (ECLIA). Urine $\mathrm{C}$ peptide immunoreactivity (CPR) as a marker of intrinsic insulin production was also measured by an ECLIA by SRL, Inc. (Tokyo, Japan). Estimated glomerular filtration rate (eGFR) was calculated by the Modification of Diet in Renal Disorder (MDRD) formula modified for Japanese (Imai et al. 2007). Metabolic syndrome was diagnosed by the Japanese criteria (Taniguchi et al. 2007) and the criteria of National Cholesterol Education Program modified for Asians (Grundy et al. 2005). Insulin resistance was evaluated by a homeostasis model assessment of insulin resistance (HOMA-IR), which was calculated by a formula [FPG $(\mathrm{mg} / \mathrm{dl}) \mathrm{x}$ fasting IRI (F-IRI) $(\mu \mathrm{U} /$ $\mathrm{ml}$ )/405] (Matthews et al. 1985) in patients with FPG of lower than
$160 \mathrm{mg} / \mathrm{dl}$ and not treated with any anti-diabetic medications.

Visceral fat area (VFA) and subcutaneous fat area (SFA) in the abdomen and fatty liver were measured by cross-sectional CT scan using multislice CT (Aquilion 16, Toshiba, Tokyo, Japan), as reported previously (Ishii et al. 2005). Fatty liver was determined by CT attenuation, and clinical fatty liver was defined as $<0.9$ of the ratio of liver/spleen CT number (L/S ratio) (Fujiwara et al. 2005), which correlated well with hepatic fat infiltration of more than $30 \%$ (Saitoh et al. 1988).

Data are presented as means \pm S.D., unless otherwise indicated. Statistical significance was analyzed by Mann-Whitney test and $\chi^{2}$-test. Spearman's rank order correlation coefficient was used to examine associations of variables with serum levels of TSH, FT4 and FT3. Multiple regression analysis and logistic regression analysis was used to find independent variables for FT3 and MetS, respectively. Statistical analysis was performed by using Dr. SPSS II (SPSS Japan Inc., Tokyo, Japan) and a $P$ value $<0.05$ was considered significant.

\section{Results}

To investigate relationships between thyroid hormones and various clinical variables, we first analyzed the correlation coefficients between serum thyroid hormone levels and various variables for all the subjects $(n=301)$. As shown in the Table 1, TSH, FT4, FT3, and FT3/FT4 ratio correlated with various metabolic variables to varying degrees. Among them, FT3 levels were correlated with more numbers of the variables as compared with TSH, FT4, and FT3/ FT4, i.e., positively with BMI, VFA, SBP, DBP, eGFR, TG and urine CPR, whereas inversely with age, HbA1c, and liver/spleen (L/S) CT ratio.

Then, we focused on FT3 for a further analysis. Because serum FT3 levels showed normal distribution (average \pm s.D., $2.90 \pm 0.48 \mathrm{pg} / \mathrm{mL}$; median, $2.89 \mathrm{pg} / \mathrm{mL}, n$ $=301$ ), and the average and the median was almost equal, the median was used to divide the subjects to two groups with lower and higher serum FT3 levels. Table 2 shows the

Table 1. Correlation coefficients ${ }^{\mathrm{a}}$ between thyroid hormones and various clinical variables.

\begin{tabular}{lcccc}
\multicolumn{1}{c}{ Variables } & TSH & FT4 & FT3 & FT3/FT4 \\
\hline Age $($ years $)$ & -0.106 & -0.027 & $-0.226^{\ddagger}$ & $-0.148^{\dagger}$ \\
BMI $\left(\mathrm{kg} / \mathrm{m}^{2}\right)$ & 0.019 & $0.154^{\dagger}$ & $0.265^{\ddagger}$ & $0.189^{\dagger}$ \\
VFA $\left(\mathrm{cm}^{\ddagger}\right)$ & 0.057 & $0.149^{*}$ & $0.291^{\ddagger}$ & $0.227^{\ddagger}$ \\
SBP $(\mathrm{mmHg})$ & 0.048 & $0.155^{\dagger}$ & $0.192^{\ddagger}$ & 0.024 \\
DBP $(\mathrm{mmHg})$ & -0.034 & $0.131^{*}$ & $0.141^{\ddagger}$ & 0.049 \\
eGFR (ml/min/1.73 $\left.\mathrm{m}^{2}\right)$ & -0.111 & 0.017 & $0.247^{\ddagger}$ & $0.230^{\ddagger}$ \\
TG $(\mathrm{mg} / \mathrm{dl})$ & 0.036 & 0.098 & $0.128^{*}$ & 0.034 \\
HDL-C (mg/dl) & -0.018 & -0.095 & -0.039 & 0.018 \\
LDL-C (mg/dl) & -0.046 & 0.035 & -0.056 & -0.068 \\
FPG (mg/dl) & $-0.165^{\dagger}$ & $0.152^{*}$ & -0.043 & $-0.172^{\dagger}$ \\
HbAlc $(\%)$ & $-0.205^{\dagger}$ & 0.081 & $-0.277^{\ddagger}$ & $-0.324^{\ddagger}$ \\
U-CPR ( $\mu$ g/day) & -0.011 & -0.028 & $0.238^{\ddagger}$ & $0.235^{\ddagger}$ \\
L/S CT ratio & 0.008 & -0.054 & $-0.263^{\ddagger}$ & $-0.241^{\ddagger}$ \\
\hline
\end{tabular}

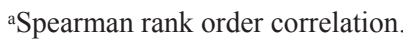
${ }^{*} P<0.05,{ }^{*} P<0.01, \sharp P<0.001$. 
Table 2. Clinical characteristics in subjects with lower and higher FT3 levels.

\begin{tabular}{|c|c|c|c|c|}
\hline \multirow[b]{2}{*}{ Variables } & \multirow[b]{2}{*}{ All subjects } & \multicolumn{2}{|c|}{ Subjects with } & \multirow[b]{2}{*}{$P$} \\
\hline & & $\begin{array}{c}\text { Lower } \\
\text { FT3 levels } \\
(<2.89 \mathrm{pg} / \mathrm{mL})\end{array}$ & $\begin{array}{c}\text { Higher } \\
\text { FT3 levels } \\
(\geq 2.89 \mathrm{pg} / \mathrm{mL})\end{array}$ & \\
\hline No $(\mathrm{M} / \mathrm{F})$ & $301(173 / 128)$ & $152(82 / 70)$ & $149(91 / 58)$ & NS \\
\hline Age (years) & $59.4 \pm 12.4$ & $62.1 \pm 10.7$ & $56.6 \pm 13.5$ & 0.003 \\
\hline BMI $\left(\mathrm{kg} / \mathrm{m}^{2}\right)$ & $25.8 \pm 5.0$ & $24.7 \pm 4.2$ & $27.0 \pm 5.5$ & $<0.001$ \\
\hline $\operatorname{VFA}\left(\mathrm{cm}^{2}\right)$ & $161.2 \pm 67.2$ & $143.6 \pm 54.5$ & $179.2 \pm 73.9$ & $<0.001$ \\
\hline SBP (mmHg) & $131.9 \pm 21.0$ & $128.9 \pm 21.6$ & $134.8 \pm 20.0$ & 0.01 \\
\hline $\mathrm{DBP}(\mathrm{mmHg})$ & $76.3 \pm 12.7$ & $74.5 \pm 13.0$ & $78.0 \pm 12.2$ & 0.019 \\
\hline $\mathrm{eGFR}\left(\mathrm{ml} / \mathrm{min} / 1.73 \mathrm{~m}^{2}\right)$ & $87.9 \pm 29.2$ & $81.9 \pm 34.0$ & $94.0 \pm 21.9$ & $<0.001$ \\
\hline $\mathrm{TG}(\mathrm{mg} / \mathrm{dl})$ & $150.3 \pm 108.7$ & $132.0 \pm 70.6$ & $168.8 \pm 134.8$ & 0.011 \\
\hline HDL-C (mg/dl) & $50.9 \pm 15.4$ & $51.6 \pm 16.9$ & $50.1 \pm 13.7$ & NS \\
\hline LDL-C (mg/dl) & $118.5 \pm 34.7$ & $119.5 \pm 33.4$ & $117.5 \pm 36.0$ & NS \\
\hline FPG (mg/dl) & $166.7 \pm 82.5$ & $173.7 \pm 107.4$ & $159.8 \pm 46.0$ & NS \\
\hline $\operatorname{HbA1c}(\%)^{b}$ & $9.5 \pm 2.2$ & $10.1 \pm 2.5$ & $8.9 \pm 1.6$ & $<0.001$ \\
\hline U-CPR ( $\mu \mathrm{g} /$ day $)$ & $78.0 \pm 55.5$ & $67.4 \pm 51.6$ & $88.7 \pm 57.4$ & $<0.001$ \\
\hline $\mathrm{L} / \mathrm{S}$ CT ratio & $1.10 \pm 0.21$ & $1.14 \pm 0.19$ & $1.05 \pm 0.22$ & $<0.001$ \\
\hline Mets (JASSO) (\%) & 78.4 & 73.2 & 83.2 & 0.036 \\
\hline Mets (NCEP) (\%) & 85.0 & 78.7 & 90.9 & 0.003 \\
\hline
\end{tabular}

aNormal range is $2.27-3.90 \mathrm{pg} / \mathrm{ml}$.

bEquivalent to NGSP (National Glycohemoglobin Standardization Program) value (Committee of Japan Diabetes Society on the Diagnostic Criteria of Diabetes Mellitus, 2010).

JASSO, Japan Society for the Study of Obesity; NCEP, National Cholesterol Education Program; NS, not significant.

Table 3. Serum thyroid hormone levels according to various medications.

\begin{tabular}{|c|c|c|c|c|c|}
\hline & \multicolumn{5}{|c|}{ Anti-diabetic medications } \\
\hline$(n)$ & $\begin{array}{l}\text { Diet only } \\
\quad(52)\end{array}$ & $\begin{array}{l}\mathrm{OHAs}^{\mathrm{a}} \\
(126)\end{array}$ & $\begin{array}{l}\text { Insulin } \\
(49)\end{array}$ & $\begin{array}{c}\mathrm{OHAs}^{\mathrm{a}}+\text { Insulin } \\
(74)\end{array}$ & $P$ \\
\hline $\mathrm{TSH}(\mu \mathrm{IU} / \mathrm{ml})$ & $1.88 \pm 1.07$ & $1.82 \pm 1.05$ & $1.84 \pm 1.06$ & $1.80 \pm 1.03$ & 0.235 \\
\hline FT4 (ng/dl) & $1.28 \pm 0.16$ & $1.28 \pm 0.15$ & $1.29 \pm 0.15$ & $1.29 \pm 0.14$ & 0.547 \\
\hline FT3 (pg/ml) & $2.86 \pm 0.50$ & $2.86 \pm 0.52$ & $2.90 \pm 0.53$ & $2.90 \pm 0.52$ & 0.322 \\
\hline
\end{tabular}

aOral hypoglycemic agents

\begin{tabular}{cccc}
\hline \multicolumn{4}{c}{ Anti-hypertensive drugs } \\
\hline$(n)$ & $(-)$ & $(+)$ & $P$ \\
\hline TSH $(\mu \mathrm{IU} / \mathrm{ml})$ & $1.89 \pm 1.08$ & $1.83 \pm 1.01$ & 0.751 \\
FT4 $(\mathrm{ng} / \mathrm{dl})$ & $1.29 \pm 0.15$ & $1.31 \pm 0.16$ & 0.163 \\
FT3 $(\mathrm{pg} / \mathrm{ml})$ & $2.85 \pm 0.50$ & $2.93 \pm 0.45$ & 0.259 \\
\hline & & & \\
& & Lipid-lowering drugs & \\
\hline & $(n)$ & $(+)$ & $P$ \\
\hline TSH $(\mu \mathrm{IU} / \mathrm{ml})$ & $1.84 \pm 1.04$ & $1.89 \pm 1.06$ & 0.737 \\
FT4 $(\mathrm{ng} / \mathrm{dl})$ & $1.30 \pm 0.15$ & $1.30 \pm 0.16$ & 0.842 \\
FT3 $(\mathrm{pg} / \mathrm{ml})$ & $2.90 \pm 0.49$ & $2.87 \pm 0.44$ & 0.399 \\
\hline
\end{tabular}


clinical variables for all the subjects and those with lower ( $n=152)$ and higher $(n=149)$ serum levels of FT3 than the median of all subjects. There were no differences in sex, HDL-C, LDL-C and FPG between the two groups (lower and higher FT3 levels). On the other hand, age and HbA1c values, and L/S CT ratio were significantly higher in the lower FT3 subjects, whereas BMI, VFA, SBP, DBP, eGFR, $\mathrm{TG}$, and urine CPR were significantly higher in the higher FT3 subjects. The prevalence of MetS, defined by both the Japanese criteria and the NCEP criteria modified for Asians, was also significantly higher in the higher FT3 subjects. However, there was no significant difference in the prevalence of MetS defined by both criteria between the subjects with the lower and higher FT4 or TSH levels than the median (data not shown). Various medications used for treatments of type 2 diabetes, hypertension and dyslipidemia were not associated with TSH, FT4 and FT3 levels (Table 3).

These data indicated that serum FT3 level had the greatest influence on the metabolic variables among the thyroid hormones (TSH, FT4 and FT3). Therefore, a multiple regression analysis was performed to find variables independently associated with FT3 levels. As shown in the Table 4, FPG, VFA and SBP were independently and significantly associated with FT3 levels. There was a tendency toward significant associations of FT3 levels with BMI, eGFR and urine CPR $(0.05<p<0.1)$. Because these variables such as FPG, VFA and SBP were components consisting of MetS and prevalence of MetS was significantly higher in the subjects with higher FT3 levels (Table 2), independent variables associated with the presence of MetS were analyzed by a multiple logistic regression analysis. Serum FT3 levels and urine CPR were independently associated with the presence of MetS among the various variables as shown in Table 5. Thus, FT3 levels and the cluster of MetS components were bidirectionally and independently associated with each other.

\section{Discussion}

In this study, we have shown that the serum FT3 level was independently and significantly associated with components of MetS such as higher FPG levels, VFA, and SBP in subjects with type 2 diabetes and euthyroidism (Table 4), while the presence of a cluster of MetS components (higher FPG levels, VFA, and SBP) was independently associated with serum FT3 level (Table 5). The results indicate the significant association between FT3 levels and presence of MetS in Japanese subjects with type 2 diabetes and euthyroidism.

The association of FT3 (Reinehr et al. 2006; De Pergola et al. 2007) with obesity has been reported in nondiabetic subjects with euthyroidism. However, a relationship between thyroid function, and obesity and MetS has not been reported in subjects with type 2 diabetes, because diabetic patients were excluded in these and other studies probably to avoid influence of hyperglycemia. Interestingly, we have shown that FT3 level is positively associated with the presence of MetS components among diabetic subjects. In addition, the presence of MetS is significantly and independently associated with FT3 levels.

On the other hand, a negative association between FT4 and MetS has been reported (Bruckert et al. 1999; Lin et al. 2005; Roos et al. 2007), although both FT3 and FT4 levels were positively associated with MetS components in our data. A reason(s) for the discrepancy between our data and other reports on a positive or negative association of FT3 or FT4, respectively, with MetS or its components is unclear. It might be related to the origin of $\mathrm{T} 3$ and stronger physiological activity of FT3 than that of FT4. T3 is converted from $\mathrm{T} 4$ by monodeiodination in peripheral tissues. Both $\mathrm{T} 4$ and $\mathrm{T} 3$ bind to binding protein in the blood, and components of them, FT4 and FT3, have physiological activity in target organs (Inada et al. 1975). A high conversion of T4 to T3 (i.e., lower FT4, higher FT3, and higher FT3/FT4) is

Table 4. Multiple regression analysis to find independent variables associated with serum FT3 levels.

Dependent variable: FT3

\begin{tabular}{lccc}
\hline \multicolumn{1}{c}{ Independent variables } & $\beta$ & $\mathrm{t}$ & $P$ \\
\hline Gender $(0 / 1)$ & 0.003 & 0.056 & $\mathrm{NS}$ \\
Age $($ years $)$ & -0.108 & -1.578 & $\mathrm{NS}$ \\
$\mathrm{BMI}\left(\mathrm{kg} / \mathrm{m}^{2}\right)$ & 0.136 & 1.791 & 0.074 \\
VFA $\left(\mathrm{cm}^{2}\right)$ & 0.203 & 2.676 & 0.008 \\
SBP $(\mathrm{mmHg})$ & 0.129 & 2.268 & 0.024 \\
$\mathrm{eGFR}\left(\mathrm{ml} / \mathrm{min} / 1.73 \mathrm{~m}^{2}\right)$ & 0.111 & 1.797 & 0.074 \\
FPG $(\mathrm{mg} / \mathrm{dl})$ & -0.174 & -3.062 & 0.002 \\
$\mathrm{U}-\mathrm{CPR}(\mu \mathrm{g} / \mathrm{day})$ & 0.107 & 1.784 & 0.076 \\
TG $(\mathrm{mg} / \mathrm{dl})$ & 0.042 & 0.663 & $\mathrm{NS}$ \\
HDL-C $(\mathrm{mg} / \mathrm{dl})$ & 0.034 & 0.581 & $\mathrm{NS}$ \\
\hline
\end{tabular}

NS, not significant.

Adjusted $\mathrm{R}^{2}=0.205, P<0.001$ 
Table 5. Multiple logistic regression analysis to find independent variables associated with presence of MetS.

Dependent variable: presence of MetS

\begin{tabular}{lccccc}
\hline $\begin{array}{c}\text { Independent } \\
\text { variables }\end{array}$ & $\begin{array}{c}\text { Regression } \\
\text { Coefficient }\end{array}$ & SE & $\begin{array}{c}\text { Odds } \\
\text { Ratio }^{\mathrm{a}}\end{array}$ & $95 \%$ CI & $P$ \\
\hline Gender & 0.004 & 0.309 & 1.00 & $0.54-1.83$ & NS \\
Age & -0.042 & 0.315 & 0.95 & $0.51-1.77$ & NS \\
eGFR & -0.821 & 0.479 & 0.44 & $0.17-1.12$ & NS \\
U-CPR & 0.806 & 0.311 & 2.23 & $1.21-4.11$ & $<0.05$ \\
TSH & 0.392 & 0.299 & 1.47 & $0.82-2.65$ & NS \\
FT4 & 0.017 & 0.307 & 1.01 & $0.55-1.85$ & NS \\
FT3 & 0.659 & 0.316 & 1.93 & $1.04-3.58$ & $<0.05$ \\
\hline
\end{tabular}

NS, not significant.

${ }^{a}$ Odds ratio: gender (male vs. female), age ( $<65$ vs. $\geq 65$ years old), eGFR ( $<60$ vs. $60 \geq \mathrm{ml} / \mathrm{min}$ $\left./ 1.73 \mathrm{~m}^{2}\right)$, U-CPR (<66.8 vs. $66.8 \geq \mu \mathrm{g} /$ day $)$, TSH $(1.64<$ vs. $1.64 \geq \mu \mathrm{IU} / \mathrm{mL})$, FT4 $(<1.30$ vs. $1.30 \geq \mathrm{ng} /$ dL), FT3 (<2.89 vs. $2.89 \geq \mathrm{pg} / \mathrm{mL})$.

implicated in patients with abdominal obesity (De Pergola et al. 2007), whose mean BMI (33.4) was extremely higher than that of our subjects (25.8). This difference in severity of obesity might be one of reasons for the discrepancy.

Danforth et al. reported that FT3 levels were correlated with basal metabolic rate (Danforth 1983). FT3 stimulates thermogenesis by increasing expression of UCP1 gene in the brown adipocytes and, in addition, expression of UCP2 and UCP3 genes in adipose tissues and muscle (Barbe et al. 2001). UCP2 and UCP3 gene expressions are decreased in subjects with hypothyroidism (Gjedde et al. 2010). Our data indicate the significant and independent association of FT3 with VFA, implying that a compensatory increase of FT3 levels to reduce visceral fat by stimulating thermogenesis is not sufficient in MetS. However, further study is necessary on this issue.

FT3 levels were significantly and negatively associated with HbA1c levels (Table 1 and 2). This is consistent with a recent report that hypothyroidism falsely raises HbA1c due to decreased erythropoiesis (Kim et al. 2010).

In this study, daily urine CPR as a marker of intrinsic insulin production was also independently associated with presence of Mets (Table 5), and tends to be associated with FT3 levels (Table 4). The multiple regression analysis indicates that independent variables associated with urine CPR was VFA, gender and eGFR, but not MetS components such as FPG, blood pressure and triglyceride, nor thyroid hormones (data not shown). These associations may be related to visceral obesity, which might induce insulin resistance and increase serum insulin and urine CPR. However, markers of insulin resistance such as HOMA-R were not measured in most of the subjects in this study, because they were under diabetic medications including oral hypoglycemic agents and insulin.

On the other hand, it has recently been reported that T3 has an anti-apoptotic and protective effect on the pancreatic beta cells (Verga Falzacappa et al. 2006, 2007). T3 activates the PI-3 kinase pathway via thyroid hormone receptor on the beta cell, and stimulates insulin secretion. This may be related to an association between higher FT3 levels, and increased urine CPR and decreased HbA1c in our study.

The limitation of this study is that it is a cross-sectional analysis in subjects with type 2 diabetes, who were treated with various medications. Further study is necessary to confirm the relationship between FT3 levels, and visceral obesity and MetS in diabetic subjects, who are stratified with and without medications, by a prospective and longitudinal study.

Finally, our study suggests that serum FT3 levels are significantly associated with the presence of MetS (or components of MetS) in not only non-diabetic but also diabetic subjects with euthyroidism.

\section{Acknowledgments}

We thank Dr. Paul Langman, Ph.D., for his kind assistance with English usage.

\section{Conflict of Interest}

There is no relevant conflict of interest to report.

\section{References}

Barbe, P., Larrouy, D., Boulanger, C., Chevillotte, E., Viguerie, N., Thalamas, C., Oliva Trastoy, M., Roques, M., Vidal, H. \& Langin, D. (2001) Triiodothyronine-mediated up-regulation of UCP2 and UCP3 mRNA expression in human skeletal muscle without coordinated induction of mitochondrial respiratory chain genes. FASEB J., 15, 13-15.

Bruckert, E., Giral, P., Chadarevian, R. \& Turpin, G. (1999) Low free-thyroxine levels are a risk factor for subclinical atherosclerosis in euthyroid hyperlipidemic patients. J. Cardiovasc. Risk., 6, 327-331.

Committee of Japan Diabetes Society on the Diagnostic Criteria of Diabetes Mellitus. (2010) Report of the Committee on the classification and diagnostic criteria of diabetes mellitus. $J$. Jpn. Diabetes Soc., 53, 450-467 (in Japanese).

Danforth, E. Jr. (1983) The role of thyroid hormones and insulin in the regulation of energy metabolism. Am. J. Clin. Nutr., 38, 1006-1017. 
De Pergola, G., Ciampolillo, A., Paolotti, S., Trerotoli, P. \& Giorgino, R. (2007) Free triiodothyronine and thyroid stimulating hormone are directly associated with waist circumference, independently of insulin resistance, metabolic parameters and blood pressure in overweight and obese women. Clin. Endocrinol. (Oxf), 67, 265-269.

Eckel, R.H., Grundy, S.M. \& Zimmet, P.Z. (2005) The metabolic syndrome. Lancet, $\mathbf{3 6 5}, 1415-1428$.

Fommei, E. \& Iervasi, G. (2002) The role of thyroid hormone in blood pressure homeostasis: evidence from short-term hypothyroidism in humans. J. Clin. Endocrinol. Metab., 87, 19962000

Fujiwara, F., Ishii, M., Taneichi, H., Miura, M., Toshihiro, M., Takebe, N., Ishida, W., Kaneko, Y., Kato, A., Suzuki, K. \& Satoh, J. (2005) Low incidence of vascular complications in patients with diabetes mellitus associated with liver cirrhosis as compared with type 2 diabetes mellitus. Tohoku J Exp Med., 205, 327-334.

Gjedde, S., Gormsen, L.C., Riis, A.L., Jørgensen, J.O., Rungby, J., Møller, N., Weeke, J. \& Pedersen, S.B. (2010) Reduced Expression of Uncoupling Protein 2 in Adipose Tissue in Patients with Hypothyroidism. J. Clin. Endocrinol. Metab., 95, 3537-3541.

Grundy, S.M., Cleeman, J.I., Daniels, S.R., Donato, K.A., Eckel, R.H., Franklin, B.A., Gordon, D.J., Krauss, R.M., Savage, P.J., Smith, S.C. Jr., Spertus, J.A. \& Costa, F. (2005) Diagnosis and management of the metabolic syndrome: an American Heart Association/National Heart, Lung, and Blood Institute scientific statement: Executive Summary. Cardiol. Rev., 13, 322-327.

Imai, E., Horio, M., Nitta, K., Yamagata, K., Iseki, K., Hara, S., Ura, N., Kiyohara, Y., Hirakata, H., Watanabe, T., Moriyama, T., Ando, Y., Inaguma, D., Narita, I., Iso, H., Wakai, K., Yasuda, Y., Tsukamoto, Y., Ito, S., Makino, H., Hishida, A. \& Matsuo, S. (2007) Estimation of glomerular filtration rate by the MDRD study equation modified for Japanese patients with chronic kidney disease. Clin. Exp. Nephrol., 11, 41-50.

Inada, M., Kasagi, K., Kurata, S., Kazama, Y., Takayama, H., Torizuka, K., Fukase, M. \& Soma, T. (1975) Estimation of thyroxine and triiodothyronine distribution and of the conversion rate of thyroxine to triiodothyronine in man. J. Clin. Invest., 55, 1337-1348.

Ishii, M., Yoshioka, Y., Ishida, W., Kaneko, Y., Fujiwara, F., Taneichi, H., Miura, M., Toshihiro, M., Takebe, N., Iwai, M., Suzuki, K. \& Satoh, J. (2005) Liver fat content measured by magnetic resonance spectroscopy at 3.0 tesla independently correlates with plasminogen activator inhibitor-1 and body mass index in type 2 diabetic subjects. Tohoku J. Exp. Med., 206, 23-30

Kim, M.K., Kwon, H.S., Baek, K.H., Lee, J.H., Park, W.C., Sohn, H.S., Lee, K.W. \& Song, K.H. (2010) Effects of thyroid hormone on $\mathrm{A} 1 \mathrm{C}$ and glycated albumin levels in nondiabetic subjects with overt hypothyroidism. Diabetes Care., 33 , 2546-2548

Krotkiewski, M. (2002) Thyroid hormones in the pathogenesis and treatment of obesity. Eur. J. Pharmacol., 440, 85-98.

Kutty, K.M., Bryant, D.G. \& Farid, N.R. (1978) Serum lipids in hypothyroidism-a re-evaluation. J. Clin. Endocrinol. Metab., 46, 55-56.

Lin, S.Y., Wang, Y.Y., Liu, P.H., Lai, W.A. \& Sheu, W.H. (2005) Lower serum free thyroxine levels are associated with metabolic syndrome in a Chinese population. Metabolism, 54, 1524-1528.

Matsuzawa, Y. (2006) The metabolic syndrome and adipocytokines. FEBS Lett., 580, 2917-2921.

Matthews, D.R., Hosker, J.P., Rudenski, A.S., Naylor, B.A., Treacher, D.F. \& Turner, R.C. (1985) Homeostasis model assessment: insulin resistance and beta-cell function from fasting plasma glucose and insulin concentrations in man. Diabetologia, 28, 412-419.

Nyrnes, A., Jorde, R. \& Sundsfjord, J. (2006) Serum TSH is positively associated with BMI. Int. J. Obes. (Lond), 30, 100-105.

Reinehr, T., de Sousa, G. \& Andler, W. (2006) Hyperthyrotropinemia in obese children is reversible after weight loss and is not related to lipids. J. Clin. Endocrinol. Metab., 91, 3088-3091.

Roos, A., Bakker, S.J., Links, T.P., Gans, R.O. \& Wolffenbuttel, B.H. (2007) Thyroid function is associated with components of the metabolic syndrome in euthyroid subjects. J. Clin. Endocrinol. Metab., 92, 491-496.

Saitoh, S., Nagamine, T., Takagi, H., Sekiguchi, T., Uehara, M., Yuasa, K., Saeki, S., Takahashi, H., Arai, T. \& Takezawa, J. (1988) [Diagnosis of fatty liver-comparison of ultrasonographic and computed tomographic findings to histological features]. Nippon Shokakibyo Gakkai Zasshi, 85, 2658-2665.

Taniguchi, A., Fukushima, M., Kuroe, A., Sakaguchi, K., Hashimoto, H., Yoshioka, I., Kitatani, N., Tsuji, T., Ohya, M., Ohgushi, M., Nagasaka, S., Isogai, O., Nakai, Y., Inagaki, N. \& Seino, Y. (2007) Metabolic syndrome, insulin resistance, and atherosclerosis in Japanese type 2 diabetic patients. Metabolism, 56, 1099-1103.

Torrance, C.J., Devente, J.E., Jones, J.P. \& Dohm, G.L. (1997) Effects of thyroid hormone on GLUT4 glucose transporter gene expression and NIDDM in rats. Endocrinology, 138, 1204-1214.

Verga Falzacappa, C., Panacchia, L., Bucci, B., Stigliano, A., Cavallo, M.G., Brunetti, E., Toscano, V. \& Misiti, S. (2006) $3,5,3$ '-triiodothyronine (T3) is a survival factor for pancreatic beta-cells undergoing apoptosis. J. Cell. Physiol., 206, 309-321.

Verga Falzacappa, C., Petrucci, E., Patriarca, V., Michienzi, S., Stigliano, A., Brunetti, E., Toscano, V. \& Misiti, S. (2007) Thyroid hormone receptor TRbetal mediates Akt activation by T3 in pancreatic beta cells. J. Mol. Endocrinol., 38, 221-233. 